\title{
Insecurity in Security: National Security in the Context of Tourism and Domestic Sustainment in the Caribbean Melissa Sobers
}

Melissa Nicole Sobers is currently a fourth year student pursuing her undergraduate degree in Criminology and Caribbean Studies at the University of Toronto. Her academic interests include studying the intersections between political activism and acts of youth resistance to various forms of neo-colonialism and Eurocentrism through a socio-legal lens. She is also fascinated by the ways in which such phenomena inform the cultural identity of certain groups in the context of the Caribbean. Melissa is an executive member of Caribbean Studies Students Union (CARSSU). Her involvement is a manifestation of her drive to educate others both on the neoliberal issues plaguing the Global South and on the undervalued vast wealth of knowledge and cultural capital that exists in these regions.

The islands of the Caribbean are encapsulated in a region of the world that is characterized by a great amount of irony at first glance. Many islands are rich with minerals and natural resources, yet many others are poverty-stricken with fragile economies that hang in the balance. The region has endless provisions, fertile ground, and lush vegetation and it is one of the largest net food importers in the world. It is a domain that contributes a significantly less amount of carbon dioxide emissions than most of the world, but it faces the highest level of vulnerability to the effects of global warming. Populations predominately from the developed countries of the world regard the Caribbean as a tropical paradise, a modern day Garden of Eden, as well as a place they often frequent in their daydreams. It is puzzling that such claims are made about a region that is statically considered to be the most violent and dangerous in the world due to skyrocketing crime rates in certain countries, specifically Jamaica, Trinidad and Tobago, and Guyana. The point of irony that will be focused on here is premised on the fact that large amounts of social and economic capital is continuously poured into maintaining a level of security for tourists, and ultimately protecting the tourism industry while there is lack of centrality and capability as to providing adequate security for the regions own citizenry. The problematic industry of tourism will be briefly analyzed to get a glimpse of where its connection lies with conducing criminality in host countries. With this context in mind, two dimensions of security will be discussed. The first pertains to the implementations put in place to protect tourists while the second focuses on current security 
measures used on national populations such as state of emergency declarations, national curfews and abuse of power by authorities. Finally, the globalization of security undertaken in the Caribbean will be examined. Such globalizing practices claim to be legitimate attempts by a 'collective force' to curb heightened levels of violence and escalating murder rates. Yet, these efforts seem to follow a habitual path that leads to functioning, effective security protection of foreign interests and traditional, malfunctioning security measures for regional societies due to a number of institutional conflicts and vestiges of colonialism.

It is important to note that the region does not resemble a homogenous entity in regards to violent crime and murder, nor do official statistics directly reflect how dangerous the region as a whole may be. Many islands demonstrate a homicide rate that increases at a relatively slower progression than their neighbors. Examples include Barbados and Dominica with a homicide rate of 11 and 10 per 100,000 people in 2007 respectively (Bowling, 15). Contrastingly, places such as Trinidad and Tobago and Jamaica reveal much higher homicide rates of 30 and 59 per 100,000 people in 2007 respectively (Bowling, 15). Despite such heterogeneity, most published work used to outline this discussion of security in Caribbean societies and the realm of tourism have assumed the opposite and generalized theoretical standpoint about the region. This is also because it is quite difficult to identify the specific practices of each country's local security agenda. Thus, taking into consideration that each island is unique and manifests conditions that set them apart from the wider Caribbean space, the aim of this discussion is to capture the general problems of security, tourism dependency, and crime that are commonplace within the region.

Tourism can be seen in a very different light when its guise of providing opportunities for national growth and development to host countries is put to the wayside. For the Caribbean, and other countries of the global south, tourism is the institutionalization of injustice. Being a tourist, described best by Jamaica Kincaid (1988), is a crime against humanity that has the power to enforce longstanding historical conditions of asymmetrical power relations that exist in social and economic forms. Countries have been cornered into accepting the industry as a main source of dependency for earning foreign revenue (Pattullo, 9). This has caused the region to put the needs of tourists ahead of their own populations in order to sustain the business of tourism. The popular discourse that is held 
is that tourism will provide a range of jobs to locals, use locally grown produce to be served in hotels, and generate hard currency for local vendors through their exchanges with tourists and with the receiving of tips. This is hardly the reality when resorts and other tourist facilities become established in the region. The World Trade Organization's implementation of the General Agreement on Trade in Services (GATS) has allowed many transnational corporations in the business of tourism the power and legality to bypass the multiplier effect described above which could act as a linkage for foreign capital to flow into the region (Kalisch, 90).

Another leakage between tourism revenue and the local economy is the underproduction of the manufacturing sector for domestic use (Pattullo, 39). The fact that the tourism industry is directly affected by the fluctuation of other economies and exchange rates can put a great deal of stress on the inhabitants of a country as well (Pattullo, 47). This ultimately puts the host country's economy in a vulnerable position in relation to the dominant tourist-providing economies of the North and the seasonality of the industry. Although there is no hard evidence to claim that such exploitative practices of the tourism industry specifically contribute to the crime rate of host countries, it is basic human nature to have some level of social tension come out of areas that are continuously and systematically manipulated and utilized for the wealth and material benefit of others as well as foreign entities.

A more direct phenomenon that can be said to cause an explosion of frustration horizontally, subsequently manifesting itself in the form of crime, is the 'demonstration effect' that usually occurs as a by-product of tourism (Albuquerque and McElroy, 1986). This happens when locals are exposed to the conspicuous spending of seemingly wealthy tourists on luxury amenities that are only imaginable and out of reach to citizens of the impoverished host country. As explained by Villamil (1976) the demonstration effect occurs when there is "the disequilibrium between the fast rate of consumer preference shifts and the slow pace of productivity change". Tourists not only draw attention to the economic disparities that exists between their contact zone and that of the host country, they also demonstrate a sense of power and high status in relation to the locals. As described by Benjamin Bowling (2010), the low wages that are paid to workers cause social tensions from a predominately black service staff catering to a white visiting population (48, Bowling). This sort of 'leisure imperialism' or 
'natural hedonism' acts to reinforce and perpetuate colonial stereotypes whilst degrading the cultural identity of the Caribbean as explained by Mimi Sheller (2004), thus contributing to the development of socioeconomic dysfunctions like sex tourism and the like.

With so many adverse effects accompanying the implementation of tourism in the region it is difficult to grasp why a state would logically want to protect and sustain such an industry. As explained above, the dependence these countries have on the business of tourism to generate foreign capital is paramount, thus blurring their vision of capably seeing any other way to overcome their underdevelopment, while regional collaboration and cooperation would be a much better suited answer to their woes if implemented properly. A major way that local governments sustain an active tourism industry in their country is by avoiding bad publicity that could cause fear in tourists and potential investors who are interested in the region. Crime against tourists is a major source of negative press against a country and is usually propagated to reflect the entire island as a barbaric and murderous domain which ultimately will produce detrimental effects for the rest of the Caribbean as well.

In the 1980's the victimization of tourists began to emerge as a problem in Jamaica, therefore the government saw a necessity in concentrating efforts and resources towards the security of foreigners despite the fact that the number of crimes against tourists was relatively minor in relation to the crime rate outside of the tourist enclave or rather, within the domestic sphere. Jamaica became the leading country in the establishment of enclave tourism which has been exported throughout the region since the 1980's (Albuquerque and McElroy, 972).

Enclave tourism is manifested in the form of all-inclusive or self contained resorts that virtually isolate tourists from contact with locals who do not work directly for the hotelier. It is meant to create an 'ecological bubble', according to Erik Cohen (1978), which is essential for making the experience of the tourist smooth and in an accustomed environment. This includes the implementation of upgraded security strategies which comes at an expensive cost. According to Pattulo (1996) these efforts are "[f]unded partly by aid but also by expensive borrowing, they must all be paid for in the end by local people through some sort of taxation" (Pattulo, 31). Tourism 
chains such as Sandals and Couples implemented large fences and gates that act to secure visiting foreigners, keeping them in safely surrounded havens. Large amounts of financial resources also go into the training and hiring of full-time security guards to surround the enclosed resorts, heightening the level of exclusivity felt by local citizens through the materialization of existing social boundaries and divisions. Not only do these measures keep tourists from experiencing crime, it also keeps them from experiencing a genuine cultural and physical sense of the island. Enclave tourism has managed to extend its reach of discrimination by limiting the use of certain geographical areas, such as beaches, waterfalls, and natural gardens, to tourists only. Local street vendors, service operators, restaurants and boutiques are unable to have any sort of contact with foreign visitors through these mechanisms, thereby making it virtually impossible to receive monetary revenue from these groups. This sort of separation adds to the horizontal animosity created between inhabitants and guests.

As explained by Albuquerque and McElroy (1999), stakeholders of multinational corporations in the tourism industry and tourists themselves felt no sort of ambivalence or discomfort towards the security measures mentioned above, nor did they oppose to the appeal made by the Jamaica Hotel and Tourist Association to the Prime Minister in 1992 regarding the use of army patrols around resorts and other such tourism areas (Morris, 1992). Such propositions are far from sustainable in terms of keeping the tourists attracted to the natural beauty of the Caribbean and receiving an authentic island experience (Albuquerque and McElroy, 980). These measures that ultimately act to create a state within a state do not speak to the rest of the country's problem of crime. They artificially mask the real situation in order to market the region as being safe and enthusiastically content to be utilized and enjoyed by foreign bodies. Overall, these security measures are not feasible because they diminish innumerable links that offer revenue to the local economy and are ultimately aimed at preserving the interests of state policies. These measures also strengthen the deepening frustrations of the marginalized citizenry and acts to displace crime to other parts of the society, thus adding to the dangers that locals face.

With all the aforementioned institutionalized measures put in place for tourist protection, one may be surprised at the fact that no such centralization or effectiveness exists when it comes to security measures for the majority of the national body in the 
Caribbean region. With continuously swelling homicide figures on some islands in the region, governments have assumed a tough-oncrime attitude that consistently wavers when it comes to implementation and effectiveness therein. There has in fact been millions of dollars spent on security in the Caribbean over the last two decades, yet it has not seemed to stop serious and armed violence in the region. Funding for this national security has in fact managed to suck scarce government resources away from education, health care and poverty alleviation. The situation appears to have "escalated to bloody civil war proportions" with the highest homicide rates in the world (Bowling, xi).

Thus far, the region has focused its attention on using prohibition regimes such as nation-wide curfews, states of emergency and basic attendant security practices, as well as concentrated numbers of officers in certain areas, usually protecting wealthy neighbourhoods most effectively. These practices have been implemented with little reflection on the advice of criminological experts. Curfews can have the effect of displacing violent crime from happening out on the streets to inside the home, most often against women and children. This type of crime is much harder to investigate by authorities as it usually goes unreported due to the nature and circumstances of domestic crime and the relationship that exists between the victims and offenders. The concentration of police officers in alleged 'hot spots' of criminal activity does not act as a legitimate effort either due to the fact that it can also displace crime to other areas of the country once criminals realize the elevated presence of security in those particular places. There has also been the use of overt authority and abuse of power when police deal with citizens of lower socioeconomic status as a means of controlling them to prevent crime from eventually occurring. This is seen in the broadening of powers for authorities to conduct search and seizure operations and make arrests on ambiguous grounds. Such regulations can most often have the adverse effect of stimulating crime instead of diminishing it by eroding the relationship between people and the state - represented in this case by law enforcement officials.

This phenomenon is exasperated in Caribbean nations that are politically polarized and therefore already have a removed sense of trust for state affairs. There are also no institutional mechanisms that act to deliver accountability and transparency to the public on the part of police forces, thus leaving more reason for communities 
to feel unsafe and distrustful of their local state services. It can be said that the disproportionate manner in which security resources are arranged to better serve the privileged and elites of the Caribbean region ultimately speaks to the abundance and free amble of political corruption. According to Bowling (2010), "[a]t worst, government ministers and businessmen are seen as complicit, profiting personally from the organized crime that penetrates to the very heart of commercial and political life on the islands" ( Bowling, 5).

Aside from political corruption and destabilization, it is difficult for these impoverished nations to match the financial and technological strength of international criminal organizations when implementing national security. Caribbean governments have come to realize that if the problem of crime continues to escalate at such an alarming rate it will scare away investment and curtail any potential for economic growth. Quite soon nations can slip into even worse social and economic deprivation on all levels of the social stratum. In fact, the CARICOM Task Force on Crime and Security outlined in their summary report that the issue of security should be looked at as a "developmental and social issue". They have stated that, "Foreign investment, which is an essential requirement in the development process, is impeded by the social instability which exists in several member states. Social stability, on the other hand, can only be achieved if there is specific investment in the communities" ( Sanders, 389). Therefore governments have recently been looking into transnational solutions for this omnipotent problem that has only intensified throughout $21^{\text {st }}$ century.

Transnational policing is a recent development that has been implemented to change the Caribbean's organization of security. It involves the collaboration of national police officers with other officers that are transatlantic. The system works by having local police officials of a nation meet with overseas liaison officers. These officers are most often from the United States and Britain and are usually stationed in the Caribbean for three to four years at a time for the purpose of aiding local forces in developing ideas that will work for their situation of crime in their home country (Bowling, $\mathrm{X})$. An important aspect of this system is that developed countries with foreign interests in the Caribbean have offered to partially fund the implementation of new security measures suggested by liaison officers. This system of policing can be looked at as a positive thing since its advice is most useful in the battle against a specific criminal problem that has started coming to light in the region. This is the 
problem of organized criminal activity being conducted by deportees coming from the United States and Canada where they have been exposed to advanced criminal skills that are unfamiliar to the Caribbean region's police forces.

With this new effort to formulate and introduce improved security measures to the region, many problems come to mind. One issue is the fact that these foreign liaison officers have little contextual background knowledge regarding the region. This makes it difficult for them to actually and pragmatically suggest a protocol that would work in the context of the Caribbean, keeping in mind all of its complexities and its place in history which ultimately contribute to its present situation. This lends us the memory of previously exported ideas from metropolises that had adverse effects for the underdeveloped masses such as the economic teachings of the Chicago Boys in Latin America from the School of the Americas and, more locally, the operation of the Moyne Commission in the British Caribbean. These officers tend to act with 'occidentalism', described by Maureen Cain (2000) as "presuming sameness in key cultural categories, practices and institutions" across the Caribbean region (Cain, 239).

Another point of conflict is that the security measures devised by the liaison officers may not be effectively or successfully implemented due to the fact that their suggestions are based on systems that exist in well equipped, developed nations, not underresourced police units like those of the Caribbean (xi, Bowling). Although funding from international sources has been promised, negative implications have come out of this arrangement as well. According to Bowling (2010), "the security agenda is set by those who provide the resources, and although there are mutual interest, deployment is geared firstly to the interests of the metropolitan countries rather than those of the Caribbean" (Bowling, xi). There has been an overflow of ideas geared towards preventing drug trafficking and drug-related crimes under the supervision and suggestions of liaison officers. This is ultimately because United States, Canada and Britain are mostly interested in stopping the flow of drugs from reaching their shores above any other concern. According to Ronald Sanders (2003), "It is significant that, when the international community was providing assistance, the entire focus was on restricting the supply of drugs, with little or no attention to the problems that transhipment was creating for Caribbean countries themselves" (Sanders, 386). Therefore we see that through 
this push for transnationality in crime prevention, the Caribbean region's national body is once again made into a secondary concern.

Community policing has also been an idea put on the table for dealing with crime because of its ideological prevalence in Canada and the United States. This approach of strengthening the partnership between citizens and police may look good on paper, but must be thought about critically in the context of certain Caribbean nations, especially those which are racially divided such as Trinidad and Tobago and Guyana. There is also the question of how much organizational capability exists in local police services to propel community policing programs (Deosaran, 138). This can pose systematic setbacks if the project is simply implemented without dealing with the social roots of the country's problem. A harsher mechanism that has been suggested includes regional associations among police, military, and Customs. Their course of action has included the use of military force in towns and villages alongside police officials, but this has acted in some cases to blur the responsibilities of the police and military when it comes to maintaining order in society. Giving these forces increased amounts of authoritative reign enables the consent to retain a culture of control as opposed to one that assumes the responsibility to be the caretaker of its citizenry (Bowling, $\mathrm{x}$ ). The aforementioned overseas liaison officers behind all of these projects ultimately add to the threat of neocolonialism by extending the global policing power of developed countries. In other words, a link is created between the islands and the metropolis in a way that facilitates international, indirect governance (Bowling, 10). Drawing on the historical undertones of this practice, Bowling (2010) explains that "reliance on the former colonial masters and the world's sole superpower comes at a cost of national sovereignty and self-determination" (Bowling, xi).

In contrast, there has been a push for regional collaboration to solve the problem of crime collectively, relying on other Caribbean nations who experience a similar struggle as opposed to neocolonial structures in developed, and unfamiliar countries. Pooling resources to select the best officers from all regional forces to form a special response unit has been suggested. The idea of regionalized transnational links between local police sectors is important because as Maureen Cain (2000) states, the crime-fighters would be "indigenous but globally aware". Antigua and Barbuda's Prime Minister, Lester Bird, proposed in 2001 the formation of a Regional 
Authority to devise anti-narcotic strategies to target the root of much of the Caribbean's crime. He also called for a Caribbean Drug Control and Crime Prevention Office (CDCCP), working towards a Council of Ministers of National Security. "He envisaged that the Office 'would be charged with the responsibility of devising and approving a regional anti-narcotics and crime prevention strategy; managing the policy including supervising the drug enforcement units; drafting common anti-narcotics legislation; negotiating cooperation treaties with other countries; executing an educational programme against drugs, and mounting a diplomatic démarche on behalf of all Caribbean states"' (Sanders, 387). This call for regional mechanisms to deal with crime is a step in the right direction however, considering how unorganized and ineffective the CARICOM Single Market Economy and Free Movement of Persons Regime has been it is no surprise that this project has not been fully realized either.

Regional entities that have in fact been formed include the Regional Security System (RSS) and the Association of Caribbean Commissioners of Police (ACCP) which act to curb civil emergencies as well as respond to natural disasters (Bowling, 10). What makes these organizations problematic is that they are disguised under regional claims but are actually created and funded by American, Canadian, and British institutions, thus, once again, 'he who pays the piper calls the tune'. In other words, the role of security is skewed to center around the priorities of those supplying the financial or resource aid.

It is clear that the region of the Caribbean has come to depend for its livelihood on entertaining people who want care-free holidays to escape the harsh realities of life. Therefore it is understandable that some effective security strategies or provisions be made to protect visitors. However, the problem is that the system of tourism continually abuses and exploits Caribbean nations by inadvertently perpetuating crime among local inhabitants, thus making it ironic that governments allocate scarce national resources to protect such an operation at grave social costs to their own populations. The fact is that state interests of potential development in this derogatory system is the reason behind implementing expensive security measures, despite the great costs to domestic society. The efforts used to fight the increasing crime rates or bids for protective measures for the citizens of Caribbean nations are sadly not as effective or as highly prioritized as those of the tourists. 
Many factors contribute to the unsuccessfulness of national security practices beginning with political corruption and preoccupations on economic dependency. Harsh, weakly informed apparatus of national curfews and the granting of more authority to officers for making ambiguous stop and searches and arrests also act to diminish any success at providing a safer environment. The limited amount of resources available to Caribbean security forces is another major roadblock for making the region a safer place. The globalization of security has not helped the local situation much either. The foreign-centered agenda of overseas liaison officers, their lack of regional knowledge and historical information, and their incompatible suggestions for security in the Caribbean setting has done little to curb the situation of crime that locals fearfully face on a daily basis. There is also the major problem of deepening neocolonial ties with developed nations through the use of external aid. Although solutions have been ideologically and theoretically sketched out involving the regional Caribbean society, actual efforts and implementations have yet to arise in CARICOM's agenda, making it impossible for citizens to hold out hope in their governmental systems. The mechanism that have been implemented thus far have simply worn the mask of regionalism but are actually devised and funded by the metropolitan countries of Britain, Canada and the United States. At this rate, the outlook on the Caribbean's problem with crime is not hopeful. This should act as a wake-up call for governments to truly pay attention at the detrimental effects that are emanating from sources of 'development' and 'socioeconomic growth', namely the tourism sector. Instead of protecting this losing cause, governments should focus their attention on regional strategies for growth and sustainment which is their ultimate weapon for curbing the situation of crime. 


\section{Work Cited}

Biko Agozino, Ben Bowling, Geofrey St. Bernard, and Elizabeth Ward (2009), "Guns, Crime and Social Order in the West Indies", Criminology and Criminal Justice, Vol 19 (3): 287-305

Bowling, Benjamin. Policing the Caribbean. Oxford: Oxford University Press, 2010. Print.

Cain, Maureen. "Orientalism, Occidentalism and the Sociology of Crime." British Journal of Criminology 40 (2000): 239-260. Academic OneFile. Web. 1 Apr. 2012

Cohen, Erik. "The Impact of Tourism on the Physical Environment." Annals of Tourism Research 5 (1978): 215-232. Print.

Deosaran, Ramesh. "Community policing in the Caribbean: Context, community and police capability." Policing: An International Journal of Police Strategies \& Management 25.1 (2002): 125-146. Scholars Portal Journals. Web. 1 Apr. 2012.

Kincaid, Jamaica. “A Small Place.” New York: Farrar, Straus, and Giroux, 1988. Print.

McElroy, Jerome, and Klaus De Albuquerque. "The Tourism Demonstration Effect in the Caribbean." Journal of Retailing and Consumer Services 2.4 (1986): 31-34. Scholars Portal Journals. Web. 1 Apr. 2012.

McElroy, Jerome, and Klaus De Albuquerque. "Tourism and Crime in the Caribbean." Annals of Tourism Research 26.4 (1999): 968-984. Print.

Morris, M., "Army Patrols Tourist Areas." The Daily Gleaner (August 20, 1992): 1. Web. 1 Apr. 2012.

Pattullo, Polly. Last Resorts: the cost of tourism in the Caribbean. London: Cassell; 1996. Print.

Sanders, Ronald. "Crime in the Caribbean: An overwhelming phenomenon." The Round Table: The commonwealth journal of International Affairs 92.370 (2003): 377-390. Taylor \& Francis Online. Web. 1 Apr. 2012. 
MELISSA SOBERS| INSECURITY IN SECURITY

Sheller, Mimi, "Natural Hedonism: The invention of Caribbean islands as tropical playgrounds," In Sandra Courtman (ed) Beyond the blood, the beach \& the banana: new perspectives in Caribbean studies. Kingston: Ian Randle, 2004. 170-185. Print.

Villamil, J. "Tourism in the Caribbean", Washington: UNESCO/IBRD. 1979. 